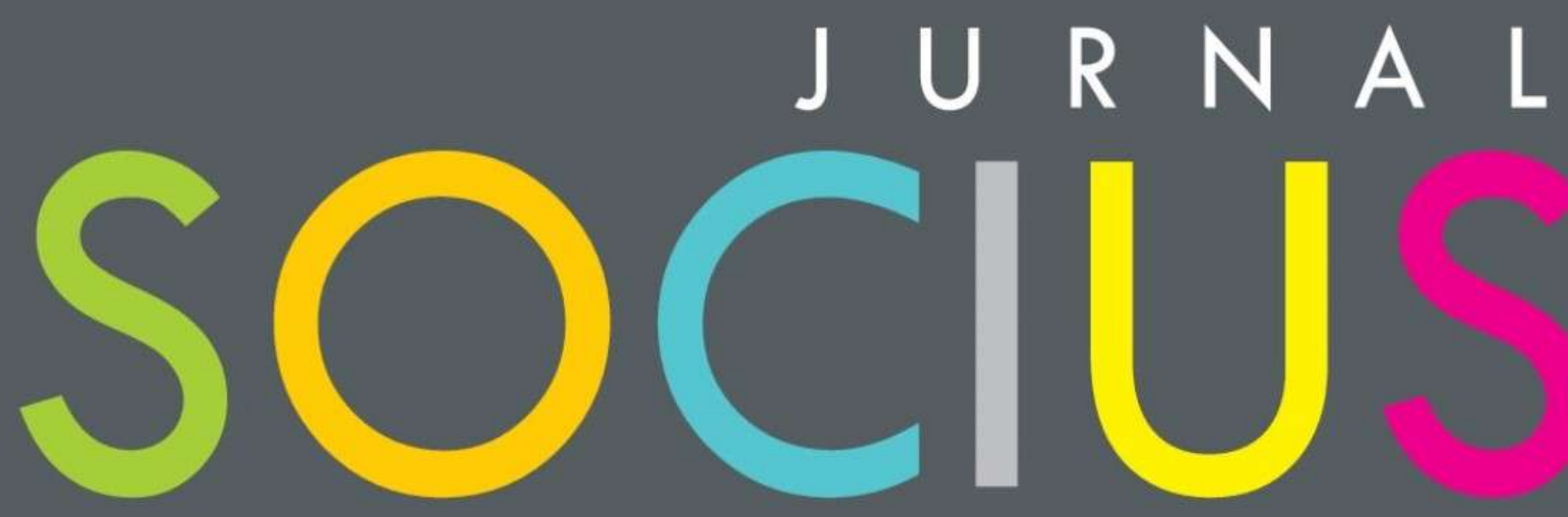

Journal of Sociology Research and Education

DITERBITKAN OLEH :

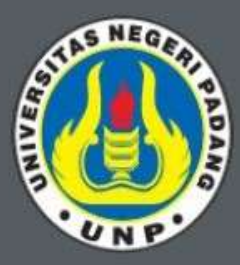

LABOR JURUSAN SOSIOLOGI FAKULTAS ILMU SOSIAL UNIVERSITAS NEGERI PADANG

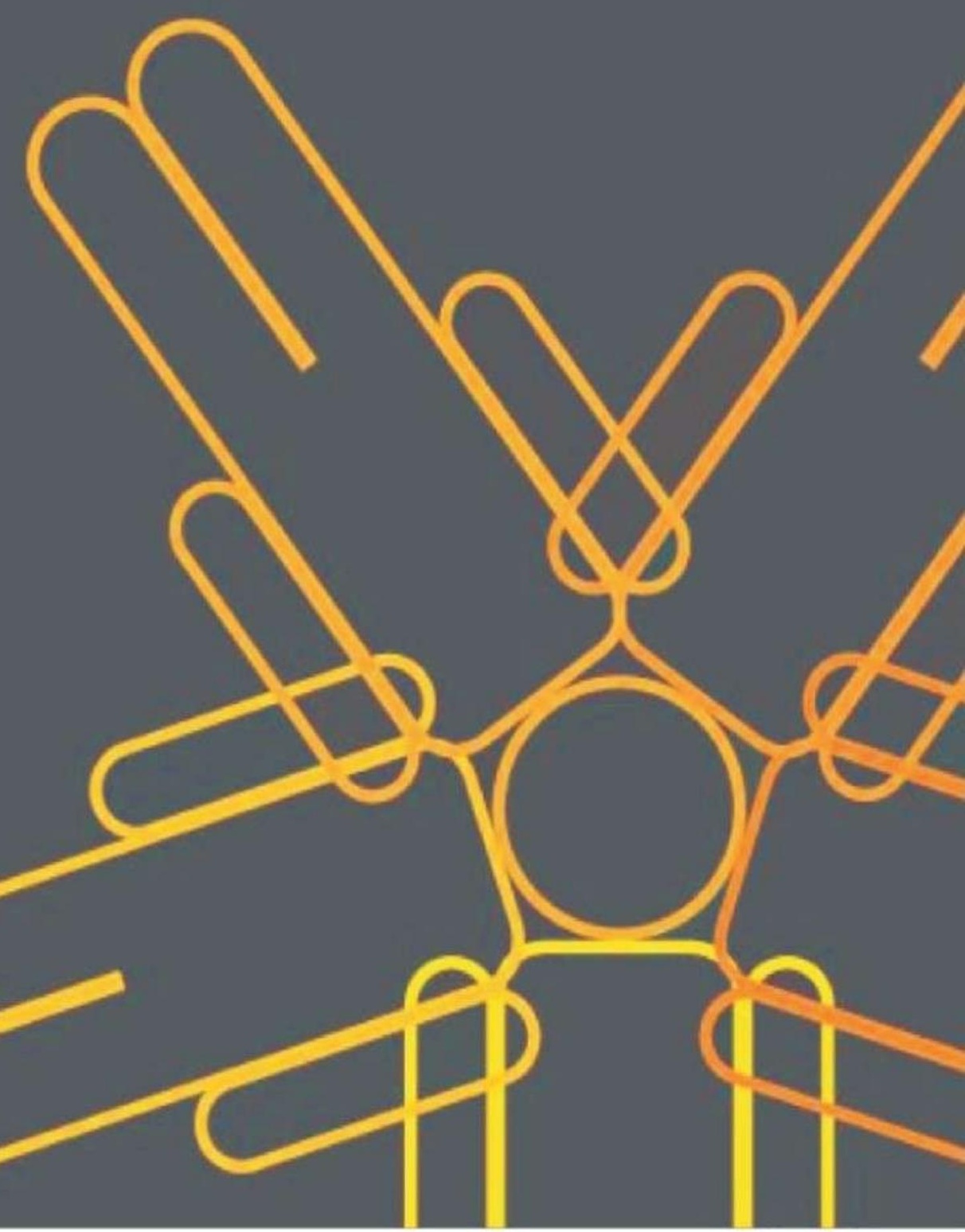




\section{SOCIUS}

Vol. 4, No.2, Th. 2017

ISSN : 2356-4180 (cetak)

2442-8663 (online)

\begin{tabular}{|c|c|}
\hline $\begin{array}{c}\text { REDAKSI } \\
\text { JURNAL SOCIUS }\end{array}$ & DAFTAR ISI \\
\hline $\begin{array}{l}\text { Ketua Dewan Penyunting : } \\
\text { Dr. Erianjoni, S.Sos., M.Si. } \\
\text { Wakil Ketua Dewan Penyunting : } \\
\text { Selinaswati, S.Sos., M.A., Ph.D. }\end{array}$ & $\begin{array}{c}\text { Abdul Salam } \\
\text { Bulan Bintang dibawah Kuasa Beringin: Parmusi } \\
\text { Padang Pariaman Masa Orde Baru } \\
\text { Halaman 61-73 }\end{array}$ \\
\hline $\begin{array}{c}\text { Dewan Penasehat: } \\
\text { Prof. Dr. Syafri Anwar, M.Pd. } \\
\text { (Universitas Negeri Padang) } \\
\text { Prof. Dr. Mestika Zed, MA. } \\
\text { (Universitas Negeri Padang) } \\
\text { Prof. Dasman Lanin, M.Pd., Ph. D. } \\
\text { (Universitas Negeri Padang) } \\
\text { Bakhrul Khair Amal, SE.,M.Si. } \\
\text { (Universitas Negeri Medan) } \\
\text { Prof. Dr. Ferdinand Kerebungu, M.Si. } \\
\text { (Universitas Negeri Manado) } \\
\text { Dr.rer.nat. Nurhadi, S.Ant., M. Hum. } \\
\text { (Universitas Negeri Solo) } \\
\text { Drs. Emizal Amri, M.Pd., M.Si. } \\
\text { (Universitas Negeri Padang) } \\
\text { Adri Febrianto, S.Sos., M.Si. } \\
\text { (Universitas Negeri Padang) } \\
\text { Drs. Ikhwan, M.Si. } \\
\text { (Universitas Negeri Padang) }\end{array}$ & $\begin{array}{c}\text { Delmira Syafrini dan Reno Fernandes } \\
\text { Dampak Revitalisasi Kota Sawahlunto Dari } \\
\text { Kota Tambang Menjadi Kota Wisata Tambang Berbudaya Pada } \\
\text { Kehidupan Sosial Ekonomi Masyarakat } \\
\text { Kota Sawahlunto } \\
\text { Halaman } 74-82 \\
\\
\text { Erda Fitriani, Selinaswati dan Desy Mardhiah } \\
\text { Partisipasi Masyarakat Dalam Pembangunan } \\
\text { Ekowisata Sungai Pinang } \\
\text { Studi Kasus: Nagari Sungai Pinang Kecamatan Koto IX Tarusan } \\
\text { Kabupaten Pesisir Selatan Sumatera Barat } \\
\text { Halaman } 83-96 \\
\text { Erianjoni } \\
\text { Pengembangan Materi Ajar Sosiologi Tentang Mitigasi Bencana } \\
\text { Berbasis Kearifan Lokal Di Kota Padang } \\
\text { Halaman 97-108 }\end{array}$ \\
\hline $\begin{array}{l}\text { Dewan Penyunting: } \\
\text { Dr. Eka Vidya Putra,S.Sos,.M.Si. } \\
\text { Dr. Desy Mardiah,S.Sos..S.Thi,.M.Si } \\
\text { Ike Sylvia,S.IP,.M.Si. } \\
\text { M. Isa Gautama,S.Pd,.M.Si. } \\
\text { Reno Fernandes, S.Pd., M.Pd. }\end{array}$ & $\begin{array}{c}\text { Muhammad Hidayat } \\
\text { Studi Pengaruh Kemandirian Mahasiswa Yogyakarta Terhadap Perstasi } \\
\text { Akademik: Respon } 60 \text { Mahasiswa Di Yogyakarta } \\
\text { Halaman 109-119 }\end{array}$ \\
\hline $\begin{array}{c}\text { Layout Editor : } \\
\text { Rhavy Ferdyan, S.Pd. }\end{array}$ & $\begin{array}{c}\text { Reno Fernandes } \\
\text { Adaptasi Sekolah Terhadap Kebijakan Pendidikan Inklusif } \\
\text { Halaman 120-126 }\end{array}$ \\
\hline $\begin{array}{l}\text { Technical Support: } \\
\text { Rudi Mahesa, A.Md. }\end{array}$ & $\begin{array}{c}\text { Selinaswati dan Erda Fitriani } \\
\text { Peran Sekolah Dalam Antisipasi Keracunan } \\
\text { Pangan Jajanan Anak Sekolah-PJAS }\end{array}$ \\
\hline $\begin{array}{l}\text { Alamat Redaksi: } \\
\text { Jurusan Sosiologi FIS UNP } \\
\text { Jl. Prof.Dr.Hamka } \\
\text { Kampus UNP Air Tawar } \\
\text { e-mail: } \underline{\text { sosan@ @is.unp.ac.id }}\end{array}$ & $\begin{array}{c}\text { (Studi Kasus Tiga SD Di Air Tawar Timur Padang Sumatera Barat) } \\
\text { Halaman 127-134 }\end{array}$ \\
\hline $\begin{array}{l}\text { Penerbit } \\
\text { Labor Jurusan Sosiologi } \\
\text { Universitas Negeri Padang }\end{array}$ & \\
\hline
\end{tabular}




\title{
ADAPTASI SEKOLAH TERHADAP KEBIJAKAN PENDIDIKAN INKLUSIF
}

\author{
Reno Fernandes \\ Universitas Negeri Padang \\ email: noe_nandes@yahoo.co.id
}

\begin{abstract}
Abstrak
Artikel ini dibuat diambil dari penelitian respon sekolah terhadap kebijakan pendidikan Inklusif di kota Padang. Lebih dalamnya penelitian ini ingin melihat realitas pihak sekolah merespon instruksi yang diberikan pemerintah kepada sekolah meskipun masih terdapat kekurangan sarana dan prasanana untuk menjalankan pendidikan inklusif. Penelitian tersebut berangkat dari paradigma postpositivistik dengan pendekatan kualitatif, dan metode studi kasus. Hasil penelitian menunjukan, sekolah merespon dengan menjalankan program pendidikan inklusif cendrung melakukan pemeriharaan sistem dan menjaganya tetap dalam keseimbangan (equilibrium) dengan sistem lainnya. Dalam menjaga keseimbangan (equilibrium) sekolah harus melakukan Adaptation (adaptasi) dengan lingkungan. Di kota Padang pendidikan inklusi tetap saja dijalankan oleh sekolah dengan penyesuaian yang dilakukannya dengan sumber daya yang dimilikinya.
\end{abstract}

Kata Kunci: Sekolah, Kebijakan, Pendidikan, Inklusif

\begin{abstract}
This article based on school response study of Inclusive education policy in Padang City. Furthermore, this study would like to see the reality of the schools responding government instruction given to schools although there is still a lack of facilities and infrastructure to run inclusive education. The research arranged from post-positivistic paradigm with qualitative approach, and case study method. The results show that schools respond the instruction by running inclusive education programs tend to maintain the system and keep it in equilibrium with other systems. In maintaining equilibrium the school must adapt the environment. In the city of Padang inclusive education is still run by the school with the resources-adjustment strategy.
\end{abstract}

Keyword : School, Policy, Education, Inclusive



Received: July 18, 2017

Revised: October 14, 2017

Available Online: December 1, 2017

\section{Pendahuluan}

Pendidikan merupakan alat yang sangat penting bagi setiap bangsa untuk mencari jati diri dan meningkatkan daya saing. Maka dari itu negara harus memfasilitasi pelayanan pendidikan bermutu kepada setiap warganya tanpa terkecuali, termasuk warganya yang memiliki kebutuhan khusus.

Untuk mewujudkan pendidikan untuk semua warga tanpa terkecuali. Pemerintah Indonesia telah mengeluarkan berbagai kebijakan. Salah satu diantaranya adalah pergeseran wujud pendidikan yang segregasi untuk anak-anak berkebutuhan khusus kepada pendidikan inklusif. ${ }^{1}$

${ }^{1}$ Pendidikan inklusif di Indonesia dipahami oleh sebagaian besar masyakarat sebagai sekolah inklusi dimana anak-anak yang berkebutuhan khusus (children with special needs) seperti anak yang menderita autis, tuna netra, tuna wicara dan tuna daksa dapat sekolah bersama-sama dengan anak-anak yang normal di sekolah reguler. Peraturan pemerintah nomor 19 tahun 2005 tentang Standar Nasional Pendidikan, Pasal 41 ayat (1) menya-

Jurnal Socius: Journal of Sociology Research and Education Vol. 4, No.2, Th. 2017 
Pendidikan Inklusi menjadi bagian penting dari perubahan dalam dunia pendidikan di Indonesia. Pelaksanaan pendidikan inklusi ini di dorong oleh kesepakatan Indonesia dalam konvensi internasional Education for All (EFA) dan kesepakatan deklarasi The Dakar Framework for Action. Kesepakatan dalam EFA berisi tentang Pendidikan dapat dinikmati oleh orang normal maupun orang berkebutuhan khusus.

Selanjutnya di Indonesia kebijakan pendidikan untuk anak berkebutuhan khusus diatur melalui Undang-Undang No. 20 Tahun 2003 tentang Sistem Pendidikan Nasional. Secara khusus dalam undang undang tersebut dinyatakan bahwa warga negara yang memiliki kelainan fisik, emosional, mental dan atau sosial berhak memperoleh pendidikan khusus dan penyelenggaraannya dilakukan secara inklusif atau berupa satuan pendidikan khusus. ${ }^{2}$ Kemudia pelaksanaan pendidikan inklusi diatur dalam Peraturan Menteri Pendidikan Nasional Nomor 70 tahun 2009.

Pendidikan inklusi adalah penempatan anak berkebutuhan khusus ringan, sedang dan berat secara penuh dikelas yang sama dengan siswa regular. Tujuan pendidikan inklusi ini tidak ada kesenjangan diantara anak berkebutuhan khusus dengan anak normal lainnya. ${ }^{3}$ Diharapkan melalui pendidikan Inklusi anak dengan kebutuan khusus dapat memaksimalkan potensi yang ada dalam dirinya. ${ }^{4}$

Pendidikan inklusi wajib dilaksanakan oleh pemerintah daerah di Indonesia. Ketentuan tersebut diatur pada pasal 6 Permendikbud No. 70 Tahun 2009 yang menyatakan 1) Pemerintah kabupaten/kota menjamin terselenggaranya pendidikan inklusif sesuai dengan kebutuhan peserta didik; 2) Pemerintah kabupaten/kota menjamin tersedianya sumber daya pendidikan inklusif pada satuan pendidikan inklusif; 3) Pemerintah dan pemerintah provinsi membantu tersedianya sumber daya pendidikan inklusif. Menindaklanjuti permendiknas, pada tahun 2013 Pemerintah Kota Padang mendeklarasikan diri sebagai kota Inklusi dengan menjalankan pendidikan inklusi. Dengan demikian Kota Padang harus menyediakan program yang mengakomodir kebutuhan dan kepentingan penyelenggaraan pendidikan inklusi. Hal tersebut membidangi lahirnya peraturan Walikota Padang nomor 19 tahun 2013 tentang pendidikan khusus dan layanan khusus.

Tidak hanya itu, simbol keseriusan Kota Padang dalam pelaksanaan pendidikan inklusif terlihat dari pembentukan UPT Pendidikan Khusus dan Layanan Khusus (PKLK) dan Pusat Layanan Autis Dinas Pendidikan Kota Padang pada tahun 2013. Pembentukan UPT ini bertujuan merumuskan dan melaksanakan pengelolaan pendidikan inklusi. UPT PKLK juga diberi kewenangan dalam menetapkan sekolah yang melaksanakan pendidikan inklusi, pengelolaan sarana dan prasarana pendukung, dan pengawasan pelaksanaan pendidikan inklusi. Kemudian, penyelenggaraan pendidikan inklusi di Kota Padang diatur oleh keputusan walikota Padang no 464 tahun 2014 tentang kelompok kerja pendidikan inklusif 2014 - 2019. Kelompok kerja ini ditunjuk dalam rangka suksesi pelaksaan pendidikan inklusi baik dalam bentuk mempersiapkan program, pelatihan, pendampingan dan evaluasi penyelenggaraan pendidikan inklusif di kota Padang. Dalam penyelenggaraan pendidikan inklusi Dinas Pendidikan Kota Padang mencatat hingga saat ini telah tersedia 88 Sekolah dasar menjadi penyelenggara sekolah inklusif. ${ }^{5}$ Sementara pada tingkat SMP terdapat 29 sekolah yang menjadi penyelenggara pendidikan inklusif. ${ }^{6}$

takan "Setiap satuan pendidikan yang melaksanakan pendidikan inklusif harus memiliki tenaga kependidikan yang mempunyai kompetensi menyelenggarakan pembelajaran bagi peserta didik dengan kebutuhan khusus".

${ }^{2}$ Undang-Undang SISDIKNAS (Sistem Pendidikan Nasional). Tahun 2003 pada Pasal 5 ayat 2 dan Pasal 15

${ }^{3}$ Tarmansyah. 2007. Inklusi ( Pendidikan Untuk Semua). Jakarta : Depdiknas.Hal 76

${ }^{4}$ Mega Iswari. 2007. Kecakapan Hidup Bagi Anak Berkebutuhan Khusus. Jakarta : Depdiknas Hal 2

${ }^{5}$ Keputusan kepala dinas pendidikan kota Padang Nomor : 421.4/009/DP/PKLK/2017

${ }^{6}$ Keputusan kepala dinas pendidikan kota Padang Nomor : 421.4/009/DP/PKLK/2017

Jurnal Socins: Journal of Sociology Research and Education Vol. 4, No.2, Th. 2017 
Penerapan pendidikan inklusif di kota Padang bukan berarti tanpa permasalahan. Masalah setiap sekolah relatif sama jamak terjadi di kota Padang. Seperti hasil penelitian yang dilakukan oleh Afrina Devi Marti dibeberapa sekolah Inklusi di Kota Padang. Penelitian tersebut melihat bahwa sekolah yang ditunjuk sebagai penyelenggara pendidikan Inklusif belum melaksanakan pendidikan inklusi secara baik. ${ }^{7}$

Penelitian lain juga menunjukan hal yang demikian seperti yang dilakukan oleh Leli pitriani (2017) tentang kendala guru dalam pelaksanaan pembelajaran ips di sekolah inklusi studi kasus SMPN 23 Kota Padang. Penelitian tersebut menunjukkan beberapa point penting. Pertama, kurangnya pemahaman guru mengenai karakteristik anak berkebutuhan khusus. Kedua, kurangnya penataran/pelatihan yang diterima guru umum tentang pendidikan inklusi. keadaan inilah yang menyebakan pelaksanaan pembelajaran disekolah inklusif tidak dapat dijalankan sebagaimana mestinya. Penelitian Leli pitriani juga menemukan bahwa penerimaan siswa reguler terhadap anak berkebutuhan khusus sangat kurang. Pada saat pembelajaran berlangsung siswa lain mengganggu proses pembelajaran siswa berkebutuhan khusus, bagi siswa regular kehadiran anak berkebutuhan khusus dianggap sebagai penghambat kegiatan belajar dikelas, tidak bisa diajak bergaul, dan anak yang memiliki nilai yang jel$\mathrm{ek}^{8}$

Dari berbagai data penelitian diatas terlihat bahwa pendidikan inklusif di Kota Padang masih menyimpan banyak persoalan, baik dari kesiapan sekolah, sarana prasarana dan kemampuan tenaga pengajar yang memahami kebutuhan anak inklusi, maupun penerimaan dari siswa reguler yang masih menganggap anak berkebutuhan khusus berbeda dan kerap menjadikan korban bullying. Gambaran latar belakang di atas menunjukkan bahwa sekolah inklusif pada tataran kebijakan telah dilaksanakan secara formal namun pada tataran pelaksanaannya ditingkat mikro sekolah-sekolah pelaksana belum siap secara sistem dan struktur. Untuk itu penelitian ini urgen dilakukan guna memahami respon sekolah terhadap kebijakan pendidikan Inklusif di Kota Padang.

\section{Metode Penelitian}

Penelitian ini dilakukan pada wilayah kerja dinas Pendidikan kota Padang yaitu beberapa sekolah yang ditunjuk sebagai penyelenggara pendidikan inklusi. Untuk melihat dan mengukur pelaksanaan pendidikan inklusif di kota Padang kita akan melakukan pengambilan data sekunder dan wawancara kepada beberapa sekolah. Penelitian ini berangkat dari paradigma post-positivistik dengan pendekatan kualitatif, dan metode studi kasus. Pendekatan dan metode tersebut dipilih dengan pertimbangan, bahwa ia lebih membuka peluang untuk mendapatkan informasi yang mendalam tentang respon sekolah terhadap kebijakan inklusif studi kasus di kota Padang.

Dalam melakukan pengumpulan data. Pertama dilakukan observasi. Langkah ini digunakan untuk mendapatan data tentang: kebijakan-kebijakan yang dikeluarkan oleh pemerintah kota Padang terkait dengan pelaksanaan pendidikan Inklusi. Kedua, peneliti melakukan studi dokumentasi. Teknik ini dipakai dengan maksud untuk mendapatkan data tentang dokumen-dokumen dan persyaratan legalitas fornal yang telah dihasilkan dalam rangka melaksanakan pendidikan inklusi Selain itu, juga akan dilihat tugas/kewenangan pemerintah, sekolah, guru, orang tua dan masyarakat dalam mensukseskan pendidikan inklusi. Ketiga, pengumpulan data dilakukan dengan teknik wawancara mendalam. Wawancara dilakukan untuk memahami secara detail informasi tentang penyelenggaran pendidikan inklusi di Kota Padang. Dalam konteks ini data dikumpulkan dengan menggunakan

\footnotetext{
${ }^{7}$ Afrina Devi Marti. Pendidikan Inklusif Disekolah Dasar Kota Padang.. Jupkhu. Vol 1 No 1.2012

${ }^{8}$ Leli Fitriani. kendala guru dalam pelaksanaan pembelajaran ips di sekolah inklusi studi kasus SMPN 23 Kota Padang Skripsi. Jurusan Sosiologi. Universitas Negeri Padang. 2017.
}

Jurnal Socius: Journal of Sociology Research and Education Vol. 4, No.2, Th. 2017 
teknik purposive sampling. Teknik ini dipilih atas pertimbangan, bahwa peneliti sudah memiliki pemetaan tentang informan yang dibutuhkan, yakni : Kepala sekolah, Guru, Siswa disekolah inklusi dan orang tua anak berkebutuhan khusus, orang tua siswa normal.

Kemudian data yang terkumpul dianalisis menggunakan interactive model sebagai mana yang dikembangkan oleh Miles dan Huberman. Kegiatan pengumpulan data dalam model ini meliputi tiga komponen pokok, yaitu: data reduksi data, displai data dan penarikan kesimpulan dan verifikasi.

Ketiga kegiatan ini akan dilakukan secara terus-menerus selama berlangsung proses pengumpulan data lapangan. Melalui rangkaian kegatan tersebut akan didapatkan informasi yang mendalam dan data yang valid tentang respon sekolah terhadap pelaksanaan pendidikan inklusif di kota Padang. Kemudian data yang valit itu akan dirangkai secara naratif dan kritis dalam bentuk laporan penelitian ilmiah yang bisa dipertanggung jawabkan secara metodologis.

\section{Hasil dan Pembahasan}

\section{Adaptasi Sekolah Terhadap Kebijakan Pendidikan Inklusi di Kota Padang Sebuah Tin- jauan Sosiologis}

Kebijakan pendidikan inklusif di Kota Padang merupakan kebijakan yang bersifat topdown. Maksudnya kebijakan pendidikan inklusif yang idealnya diusulkan oleh sekolah sebagai penyelenggara pendidikan inklusif, kenyataan tidak terjadi dikota Padang. Penetapan sekolah penyelenggara inklusif dilaksanakan oleh Dinas Pendidikan Kota Padang tanpa ada pertimbangan kesiapan institusi.

Pelaksanaan pendidikan inklusi di Kota Padang memperlihatkan kekuasaan dan hegemoni yang kuat pemerintah kepada sekolah. Pihak sekolah tidak dapat menolak karena penunjukkan dipandang sebagai perintah atasan yang harus diikuti. Hal ini adalah masalah relasi kuasa antara atasan dan bawahan. Sekolah hanya menunjukkan kepasrahan yang dilakukan tanpa adanya koersi. Padahal yang menunjuk dengan yang ditunjuk sebenarnya belum memahami sepenuhnya apa dan bagaimana menyelenggarakan pendidikan inklusi.

Implementasi pendidikan inklusi di Kota Padang meskipun dengan kesiapan yang minim, namun sekolah tetap menjalankan pendidikan inklusi. Keadaaan ini merupakan respon yang dilakukan sekolah menjaga sistem tetap terpelihara. Fenomena ini dapat di analisa dengan pisau teori stuktural fungsional.

Struktural fungsional memandang sekolah sebagai sistem dimana didalamnya terdiri dari sub system yang saling berkaitan. Sistem Pendidikan Inklusi terdiri dari pemerintah, kepala sekolah, guru, masyarakat, dan siswa. apabila salah satu sub sistem terganggu akan menganggu sub sitem yang lainnya. untuk mempertahankan sistem agar fungsional, maka keseimbangan sistem harus dipertahankan.

Talcot parsons merupakan teoritikus perspektif struktural fungsional yang mengemukakan skema Adaptation, Goal Atainment, Integration dan Latency. Adaptation atau disebut AGIL. Parson memandang Setiap kelembagaan dalam masyarakat melaksanakan tugas untuk menjaga stabilitas dalam struktur masyarakat.

Respon Sekolah Terhadap Kebijakan Pendidikan Inklusif dapat dianalisis dengan teori struktural fungsional. Agar kebijakan pendidikan inklusi dapat dijalankan dan bertahan disekolah di kota Padang (survive) dan berjalan dalam kerangka keseimbangan (equilibrium) maka system dalam pendidikan inklusif harus memiliki empat fungsi yang disebut dengan AGIL. Pola pemeriharaan system terlihat dari analisis kerangka AGIL .

Sekolah dalam menjalankan kebijakan pendidikan Inklusi hanya dalam rangka menjaga keseimbangan antara sub system. Pernyataan tersebut terlihat dari temuan penelitian ini. 
Meskipun sarana, prasrana dan sumber daya manusia yang terbatas dalam pelaksanaan pendidikan inklusi disekolah tetapi sekolah tetap menjalankan pendidikan inklusi.

Keseimbangan (equilibrium) tercapai dapat terlihat dari analisis skema AGIL berikut ini: Pertama, Adaptasi, di Kota Padang pendidikan inklusi tetap saja dijalankan oleh sekolah dengan penyesuaian yang dilakukannya dengan sumber daya yang dimilikinya. Hal ini terlihat dari temuan lapangan diantaranya:

\section{Adaptasi Institusi Sekolah}

Keadaan kebijakan pendidikan inklusi yang bersifat Top - down memaksa kepala sekolah harus menjalankan pendidikan inklusi disekolahnya meskipun dengan segala macam keterbatasan sekolah. Keterlambatan atau minimnya realisasi ketersediaan guru pendamping khusus oleh dinas pendidikan kota Padang dan tidak adanya pendanaan untuk gaji guru pendamping khusus, membuat kepala sekolah mengeluarkan kebijakan bahwa Guru pendamping khusus harus disediakan dan digaji oleh orang tua murid anak bekrebutuhan khusus. Selain itu minimnya pendanaan yang diberikan oleh dinas pendidikan kota Padang membuat kepala sekolah tidak mampu melengkapi sarana- prasarana penunjang jalannya pendidikan inklusi.kondisi menyebabkan pendidikan inklusi dijalankan disekolah tanpa sarana- prasarana penunjang.

Adaptation (adaptasi) yang dilakukan oleh guru mata pelajaran adalah mengajar dengan semampunya bahkan tidak jarang tujuan pembelajaran tidak dapat dicapai dalam proses pembelajaran karena waktu guru tersita oleh perilaku anak berkebutuhan khusus. Kondisi ini disebabkan guru mata pelajaran atau guru kelas tidak mengerti bagaimana cara mengajar dan melayani anak berkebutuhan khusus. Penyebab ketidakfahaman guru adalah minimnya pelatihan yang diberikan kepada guru tentang model pembelajaran inklusi, dan pengetahuan guru tentang anak berkebutuhan khusus dan metode menghadapinya.

Disisi lain guru pendamping khusus juga melakukan Adaptation (adaptasi). Keterbatasan secara kuantitas guru pendamping khusus disekolah membuat mereka melakukan tugas tidak maksimal. Guru pendamping khusus hanya dapat melayani anak berkebutuhan khusus yang berat. Sementara siswa berkebutuhan khusus lambat belajar kurang dapat diperhatikan. Keterbatasan jumlah membuat guru pembimbing khusus tidak dapat mendampingi anak berkebutuhan khusus secara maksimal didalam kelas. Kondisi ini membuat Guru Pendaping Khusus tidak dapat memantau perkembangan anak berkebutuhan khusus secara detail. Keadaan ini membuat guru pembimbing khusus tidak dapat menjalankan program pembelajaran individual untuk anak berkebutuhan khusus.

\section{Respon Sekolah dalam pencapaian Tujuan}

Selanjutnya pola penjaga keseimbangan kedua Goal Attainment (pencapaian tujuan) Keterbatasan pemahaman guru kelas tentang anak berkebutuhan khusus, keterbatasan jumlah guru pendamping khusus, keterbatasan pendanaan dan sarana prasarana pendukung pelaksanaan pendidikan inklusi disekolah membawa makna sempit tentang pendidikan inklusi. Pendidikan inklusi didefenisikan hanya sekedar formalitas. Sementara tujuan utamanya menjalankan kebijakan pendidikan inklusi seperti apa yang sudah ditetapkan oleh Dinas Pendidikan kota Padang tanpa memikirkan kualitas pelaksanaan pendidikan inklusi tersebut.

Agar sistem tetap mencapai kestabilan sistem maka perlunya menjaga komitmen dari berbagai pihak demi tercapainya tujuan tersebut. Komimen yang terbangun dalam implementasikan pendidikan inklusi di kota Padang atas dasar paksaan dari struktur yang paling atas. Kebijakan Top-down membawa komitmen atas dasar paksaan untuk menjalankan pendidikan inklusi disekolah meski dengan pemahaman dan pengetahuan terbatas. Kepala sekolah sebagai sub sistem dari sekolah membangun komitmen dengan guru untuk tetap menjalankan pendidikan inklusi meski dengan segala macam keterbatasan sumber daya pendukung, 
Sekolah juga membangun komitmen dengan orang tua anak berkebutuhan khusus.Komitmen yang dibangun adalah orang tua murid menyediakan guru pendamping khusus secara mandiri untuk anaknya dan menyediakan pembayaran sendiri kepada Guru Pendamping khusus. Agar sistem tetap mencapai kestabilan sistem maka perlunya menjaga komitmen dari berbagai pihak demi tercapainya tujuan tersebut.

\section{Pemeliharaan Pola Menuju Keseimba ngan}

Pemeliharaan pola - pola dilakukan oleh sekolah agar penyelenggaraan pendidikan inklusi tetap terlaksana adalah dengan melakukan berbagai macam stategi pelaksanaan ditengah keterbatasan sumber daya. Diantaranya: Pertama, sekolah yang telah ditunjuk oleh dinas pendidikan kota Padang tetap menjalankan perannya sebagai pelaksana pendidikan inklusi. Pemeiliharaan pola yang dilakukan sekolah sebagai penyelenggara tetap menerima siswa yang berkebutuhan khusus. Kedua, institusi sekolah dengan komitmen pelaksana pendidikan inklusi tetap menjadi pemaksa guru harus mampu menangani, mengajar dan mendidik anak berkebutuhan khusus.

\section{Penutup}

Penelitian ini menemukan bahwa kebijakan pendidikan inklusif di Kota Padang merupakan kebijakan yang bersifat top-down maksudnya kebijakan pendidikan inklusif idealnya diusulkan oleh sekolah sebagai penyelenggara, namun tidak terjadi dikota Padang, penetapan sekolah penyelenggara inklusif dilaksanakan oleh Dinas Pendidikan Kota Padang tanpa ada pertimbangan kesiapan sekolah. Implementasi pendidikan inklusi di kota Padang meskipun dengan kesiapan yang minim, namun sekolah merespon dengan tetap menjalankan pendidikan inklusi dengan segala keterbatasannya. Sekolah dalam menjalankan fungsinya cendrung melakukan pemeriharaan sistem dan menjaganya tetap dalam keseimbangan (equilibrium) dengan sistem lainnya.

\section{Daftar Pustaka}

Arikunto, Suharsini. (2010). Prosedur Penelitian Suatu Pendekatan Praktek. Jakarta: Rineka Cipta.

Bungin, Burhan. (2001). Metodologi Penelitian Kualitatif. Jakarta: PT. Raja Grafindo Persada.

Creswell, John W. (2012). Research Design: Pendekatan kualitatif, kuantitatif, dan Mixed. Terjemahan Achmad Fawaid. Yogyakarta: Pustaka Pelajar.

Direktorat PLB. (2004). Pedoman Penyelenggaraan Pendidikan Inklusi (Mengenal Pendidikan Terpadu), Jakarta: Depdiknas.

Ilahi, Mohammad Takdir. (2013). Pendidikan inklusif konsep \& aplikasi. Jogjakarta: Ar-Ruzz media.

Kristiyanti, E. (2004). "Pendidikan Inklusi : harapan bagi anak-anak berkebutuhan khusus". Jurnal perempuan, edisi 65

Moleong, Lexy J. (2010) . Metodologi Penelitian Kualitatif (edisi revisi). Bandung: PT. Raja Rosdakarya

Metthew B. Miles and A. Michael Huberman.1984. Qualitatf Data Analisis. Baverly Hills London - New Delhi: Sage Publication.

Nasution, s. (2011). Sosiologi Pendidikan. Jakarta: PT.Bumi Aksara

Jurnal Socins: Journal of Sociology Research and Education Vol. 4, No.2, Th. 2017 
Peraturan Menteri Pendidikan Nasional RI No.70 Tahun 2009 Tentang Pendidikan Inklusif Bagi Peserta Didik yang Memiliki Kelainan dan Memiliki Potensi Kecerdasan dan Bakat Istimewa

Peraturan Pemerintah Nomor 17 tahun 2010 tentang pengelolaan dan penyelenggaraan pendidikan

Olsen, H. (2003). Pendidikan Inklusif Suatu Strategi Menuju Pendidikan untuk Semua (Materi Lokakarya). Mataram: Direktorat PSLB.

Rusyani, E. (2009). Pengembangan Model Pembelajaran Inklusi Melalui Program Pendidikan yang Diindividualisasikan dan Sistem Pendukungnya. Jakarta: Prodi Teknologi Pendidikan, Universitas Negeri Jakarta.

Ramadhan, M. (2012). Ayo Belajar Mandiri Pendidikan Ketrampilan\&Kecakapan Hidup untuk Anak Berkebutuhan Khusus. Jogjakarta: Javalitera.

Ritzer, G., Goodman, Douglas J. (2011). Teori Sosiologi. Bantul: Kreasi Wacana

Sapariadi, dkk. (1982). Mengapa anak berkelainan perlu mendapat pendidikan. Jakarta: PN balai pustaka

Sugiyono. (2010). Metode Penelitian Kuantitatif dan Kualitatif dan R\&D. Bandung: Alfabeta

Sunanto, Juang. (2009). Implementasi Pendidikan Inklusif di Sekolah Dasar. Bandung: Pusat Kajian dan Inovasi Pendidikan - Sekolah Pasca Sarjana UPI.

Tarmansyah. (2007). Inklusi (Pendidikan untuk Semua). Jakarta: Depdiknas

Tarmansyah.(2012). Pelaksanaan Pendidikan Inklusif dI SD Negeri 03 Alai Padang Utara Kota Padang (Studi Pelaksanaan Pendidikan di Sekolah Ujicoba Sistem Pendidikan Inklusif). PEDAGOGI: Jurnal Ilmiah Ilmu Pendidikan.

UNESCO. (2004). Buku 1; Menjadikan Lingkungan Inklusif, Ramah Terhadap Pembelajaran, (LIRP). Jakarta: Depdiknas.

Undang-Undang Nomor 20 Tahun 2003 tentang sistem pendidikan nasional.

Yin, Robert K. (2006). Studi Kasus Desain dan Metode. Jakarta: PT.Raja Grafindo Persada 